\title{
MOCCCDTA-based Current Mode Tunable Universal Biquad Filter for Bluetooth Applications
}

\author{
Jyoti Sharma and Shantanu Chakraborty \\ Department of ECE, BIT Mesra, Jaipur Campus, India
}

\begin{tabular}{l}
\hline \hline Article Info \\
\hline Article history: \\
Received Feb 5, 2016 \\
Revised May 22, 2016 \\
Accepted Jun 8, 2016 \\
\hline
\end{tabular}

Keyword:

MOCCCDTA

Current mode

Biquad Filter

Tunability

Bluetooth Standard

\begin{abstract}
In the last decade, there has been much effort to reduce the supply voltage of electronic circuits due to the demand for portable and battery-powered equipment. Since a low-voltage operating circuit becomes necessary, the current-mode technique is ideally suited for this purpose more than the voltage-mode one. In this paper, performance of multi output current controlled current differencing transconductance amplifier (MOCCCDTA) is evaluated using $180 \mathrm{~nm}, 90 \mathrm{~nm}$ and $45 \mathrm{~nm}$ CMOS technology. It is found that the $45 \mathrm{~nm}$ CMOS-based MOCCCDTA provides highest frequency i.e. $33 \mathrm{GHz}$. Further a Universal biquad filter has been designed using a single MOCCCDTA as an active element and two capacitors. Filter offers high frequency in GHz. Tunability of all the filter outputs with respect to a bias current has been analyzed. The tunability of the filter circuit for Bluetooth applications is also shown in this work. The performances of MOCCCDTA circuit and Universal biquad filter are illustrated by HSPICE. The simulation results are found to be in agreement with the theoretical predictions.
\end{abstract}

Copyright (c) 2016 Institute of Advanced Engineering and Science. All rights reserved.

\section{Corresponding Author:}

Jyoti Sharma

Assistant Professor

BIT Mesra, Jaipur Campus

9929655006

jyotisharma@bitmesra.ac.in

\section{INTRODUCTION}

With the advent of integrated circuit technology, it has become possible to design larger electronic circuits on a single chip. Mixed-signal ICs are chips that contain both digital and analog circuits on the same chip. All the above mentioned circuits can be designed individually/ on a single chip by using either voltage mode or current mode techniques. Similarly, the general trend in CMOS technology is to make the devices smaller and smaller to increase the density and speed of digital circuits. It is also common to reduce the thickness of the gate oxide in order to increase the driving capability of the transistor [1]- [3]. In addition, the thickness reduction implies that the supply voltage must be decreased to avoid excessive electric field in the devices. Also the number of components is increasing on a single chip, but it can only dissipate a limited amount of power per unit area. Since the increasing density of components allows more electronic functions per unit area, the power per electronic function has to be lowered in order to prevent overheating of the chip [4]- [6].

Earlier the operational amplifier (OA) has served as the basic voltage mode building block in analog circuit design [1]- [3]. Voltage-mode operational amplifier (OA) circuits have limited bandwidth at high closed-loop gains due to the constant gain-bandwidth product. The moderate slew-rate of the operational amplifier limits the largesignal, high frequency operation. Also in the applications where wide bandwidth is required, low power consumption and low voltage operation are needed simultaneously. In that case, voltage-mode operational amplifier becomes too complex. Therefore, voltage mode circuits based on operational amplifier (OA) are not suitable for use in high frequency applications. Thus their limited performance as mentioned above, led the analog designer to search for other possibilities and other building blocks [7]. Voltage-mode circuits are those in which signal information is represented by voltage at the nodes of the circuit, where as in current-mode circuits, signal information is represented by current owing in the branches of the circuit. In current mode circuits (CMCs) the complete circuit response is determined by 
the currents and the input/ output signals are primarily represented in current form. CMCs have simple architecture and their operations do not depend on the supply voltages [6]- [7]. The current mode circuits also offer high linearity, wide bandwidth, lower power consumption, simpler circuitry and better high frequency performance [2,8-11].

In this work, a CMOS-based Multi Output Current Controlled Current Differencing Transconductance Amplifier (MOCCCDTA) has been presented. Performance evaluation of MOCCCDTA has been carried out using HSPICE through Transient and AC responses. Next a universal biquad filter has been designed using MOCCCDTA that is capable of generating low-pass, high-pass, band-pass and band-reject responses. Circuit uses only a single MOCCCDTA and two capacitor and no resistors. The proposed circuit offers several advantages such as minimum number of active and passive components required, appropriate for high frequency operation in $\mathrm{GHz}$ and resistor less implementation.

The paper is arranged as follows. Section II presents brief description of MOCCCDTA. Section III discusses the universal biquad filter. The simulation results of all the filter responses are discussed in section IV. The tunability of filter responses with the variation of bias current is also presented in section IV. Section V shows the tuning of band pass filter for Bluetooth applications. Section VI concludes the paper.

\section{BRIEF INTRODUCTION TO MULTI OUTPUT CURRENT CONTROLLED CURRENT DIFFERENC- ING TRANSCONDUCTANCE AMPLIFIER (MOCCCDTA)}

The MOCCCDTA consists of the current differencing transconductance amplifier (CDTA) as the basic building block. The CDTA takes two inputs Ip and In as currents and produces the current Iz at the impedence terminal. The current $I_{z}$ is proportional to the difference between the input currents. An equivalent voltage $V_{z}$ is produced on the impedence terminal due to the finite resistance of the terminal and the voltage drop across it. The voltage Vz so generated is then trans-conducted across to the output terminal and the output current thus produced is proportional to the value of transconductance across the circuit given by $g_{m}$. It has finite input resistances Rp and Rn at input terminals. These parasitic resistances are equal and can be controlled by biasing currents. The MOCCCDTA is represented by a set of characteristic equation shown in Eq.1.

$$
V_{p}=V_{n}=0 ; I_{z}=I_{p}-I_{n} ; I_{x} \pm= \pm g_{m} V_{z}
$$

where $\mathrm{p}$ and $\mathrm{n}$ are input terminals, $\mathrm{z}$ and $\mathrm{x}$ are output terminals and $g_{m}$ is the transconductance gain. The parasitic resistances $R_{p}, R_{n}$ and the transconductance gain $g_{m}$ are given by Eq. 2 and 3 .

$$
\begin{gathered}
R_{p}=R_{n}=\frac{V_{T}}{2 I_{B 1}} \\
g_{m}=\frac{I_{B 2}}{2 V_{T}}
\end{gathered}
$$

where $I_{B 1}$ and $I_{B 2}$ are the bias currents of the MOCCCDTA and $V_{T}$ is the thermal voltage . The basic building block of the MOCCCDTA is shown in Fig. 1 where Ip and In are the two input currents and Iz is the transimpedence current produced. At $\mathrm{x}$ terminal, we see that the output current is either in inverted mode or in noninverted mode which is proportional to the transconductance.

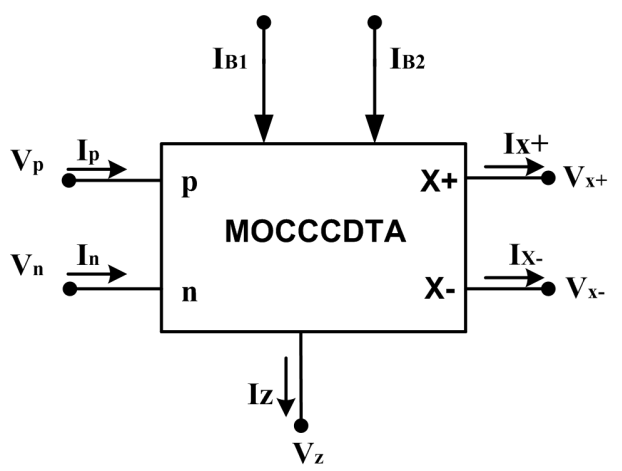

Figure 1. Block Diagram of Multi-output Current Controlled Current Differencing Transconductance Amplifier

Fig. 2 shows the internal CMOS based circuit of MOCCCDTA. Port $\mathrm{p}$ and $\mathrm{n}$ are the input ports and Z1, Z2 and $\mathrm{Z} 3$ are the positive and negative output current ports. Port $\mathrm{X}$ is also the output current port. IB1 and IB2 are the bias currents. 


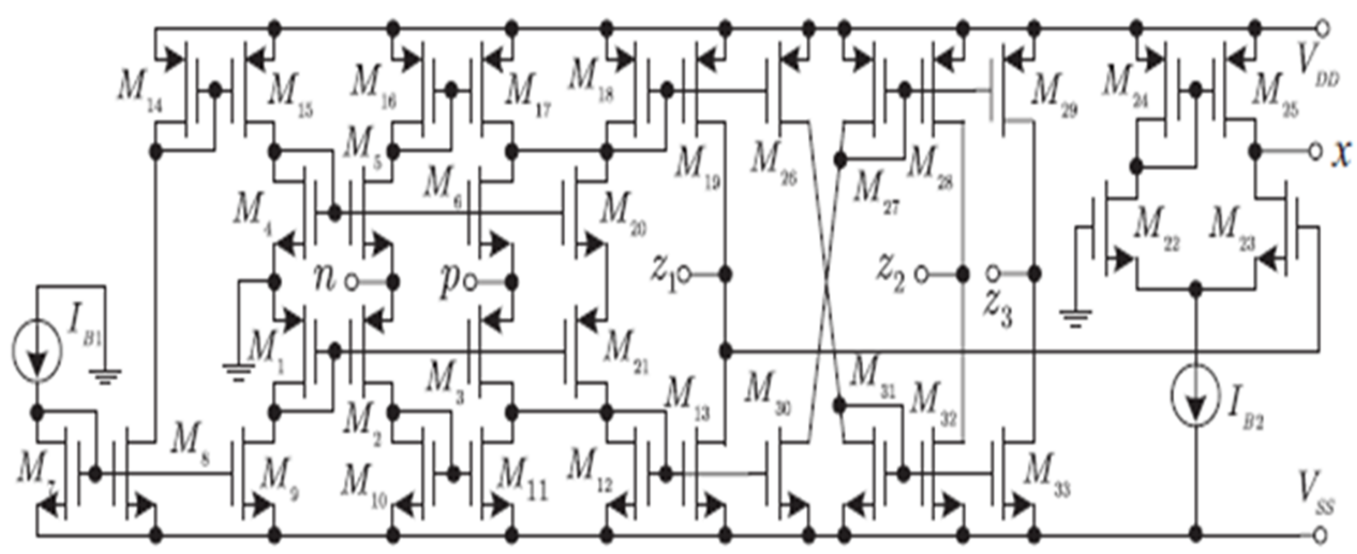

Figure 2. Internal Circuit of Multi-output Current Controlled Current Differencing Transconductance Amplifier

\section{UNIVERSAL BIQUAD FILTER}

The current mode universal biquad filter is designed using single MOCCCDTA as an active element and two grounded capacitors, which is easy to fabricate. The block diagram of the filter is shown in Fig. 3. In this filter, the multi-output CCCDTA of Fig. 2 is used where currents $I_{z 2}$ and $I_{z 3}$ are obtained in opposite directions from $I_{z 1}$. Capacitors are used for high pass and band pass applications.

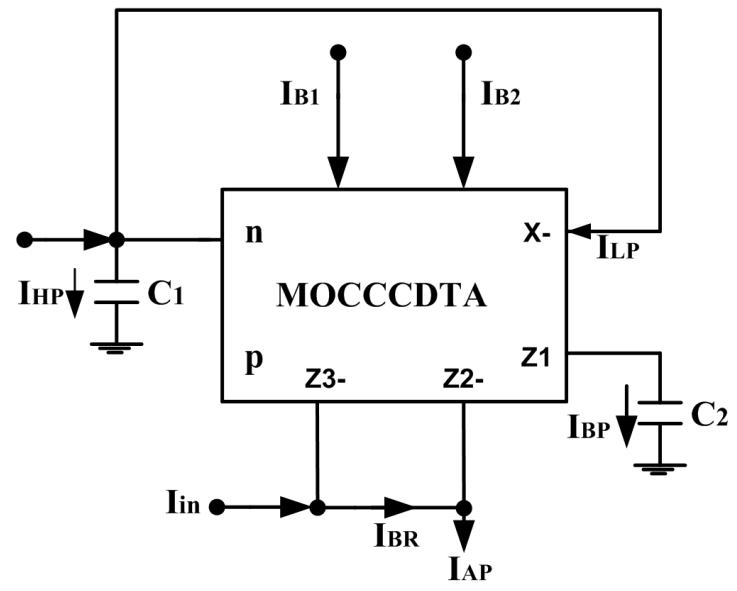

Figure 3. Block Diagram of Universal Biquad Filter

The transfer functions of high-pass, low-pass and band-pass filters are given in Eq. 4-6.

$$
\begin{aligned}
\frac{I_{H P}}{I_{i n}} & =\frac{s^{2}}{s^{2}+\frac{s}{C_{1} R_{n}}+\frac{g_{m}}{C_{1} C_{2} R_{n}}} \\
\frac{I_{L P}}{I_{i n}} & =\frac{\frac{g_{m}}{C_{1} C_{2} R_{n}}}{s^{2}+\frac{s}{C_{1} R_{n}}+\frac{g_{m}}{C_{1} C_{2} R_{n}}} \\
\frac{I_{B P}}{I_{i n}} & =\frac{\frac{s}{C_{1} R_{n}}}{s^{2}+\frac{s}{C_{1} R_{n}}+\frac{g_{m}}{C_{1} C_{2} R_{n}}}
\end{aligned}
$$

The band-reject transfer function may be achieved by IBR= Iin-IBP and is given in Eq.7.

$$
\frac{I_{B R}}{I_{i n}}=\frac{s^{2}+\frac{g_{m}}{C_{1} C_{2} R_{n}}}{s^{2}+\frac{s}{C_{1} R_{n}}+\frac{g_{m}}{C_{1} C_{2} R_{n}}}
$$


The pole frequency $\omega_{0}$ and quality factor Q are given in Eq. 8 and 9.

$$
\begin{gathered}
\omega_{0}=\sqrt{\frac{g_{m}}{C_{1} C_{2} R_{n}}}=\sqrt{\frac{\beta_{n} \sqrt{8 I_{B 1} I_{B 2}}}{C_{1} C_{2}}} \\
Q=\sqrt{\frac{C_{1} g_{m} R_{n}}{C_{2}}}=\sqrt{\frac{C_{1} \sqrt{I_{B 2}}}{C_{2} \sqrt{8 I_{B 1}}}}
\end{gathered}
$$

\section{RESULTS AND DISCUSSIONS}

The MOCCCDTA circuit has been implemented in 180nm, 90nm and 45nm CMOS technology. In order to ascertain the correct operation of the CMOS-based MOCCCDTA, transient and AC analyses were carried out using HSPICE. Transient analysis has been carried out with $100 \mathrm{MHz}$ sinusoidal input, for which the current relationship equations i.e. $I_{z}=I_{p}-I_{n}$ and $I_{x}=g_{m} V_{z}$ are successfully verified for all the three technology nodes. AC analysis for the CMOS-based MOCCCDTA reveals excellent conformity between the input currents $\left(I_{p}\right.$ and $\left.I_{n}\right)$ and the output current $\left(I_{x}\right)$ till about $1 \mathrm{GHz}, 5 \mathrm{Ghz}$ and $10 \mathrm{GHz}$ for $180 \mathrm{~nm}, 90 \mathrm{~nm}$ and $45 \mathrm{~nm}$ technology nodes respectively. The simulation results of transient and AC analyses of MOCCCDTA are shown in Fig. 4.

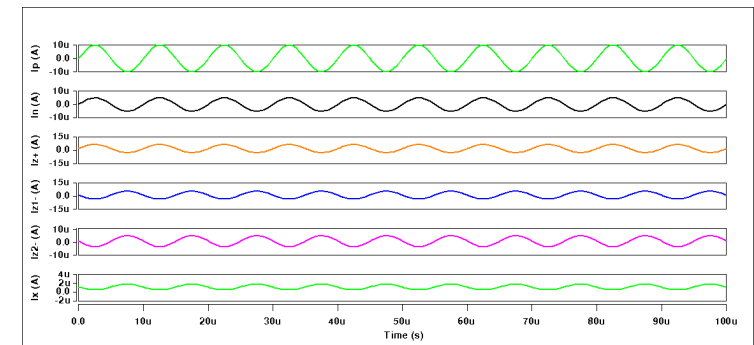

(a) Transient Response at $180 \mathrm{~nm}$ Technology

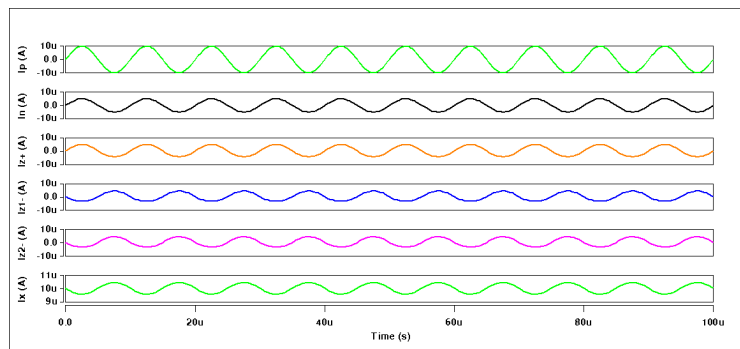

(c) Transient Response at $45 \mathrm{~nm}$ Technology

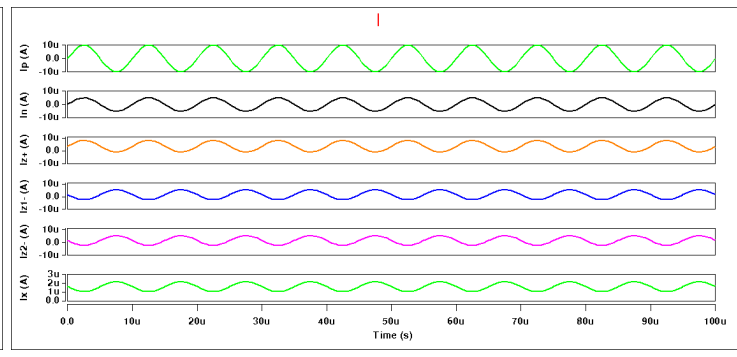

(b) Transient Response at 90nm Technology

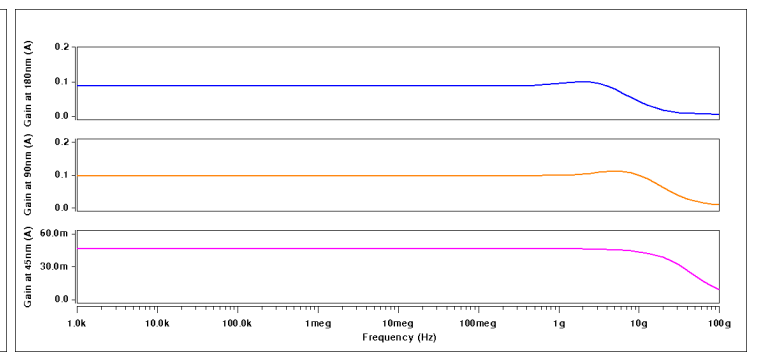

(d) AC Response at 180nm, 90nm and 45nm Technology

Figure 4. Results of HSPICE simulations for $Z+, Z-$ and X outputs of the MOCCCDTA of Fig. 2: (a)Transient Analysis at $180 \mathrm{~nm}$ (b) Transient Analysis at $90 \mathrm{~nm}$ (c) Transient Analysis at $45 \mathrm{~nm}$ and (d) AC Analysis at 180nm, 90nm, 45nm Technology

The values of power supplies, bias currents and bandwidth obtained for different technologies are shown in Table 1. It is observed that MOCCCDTA circuit offers highest bandwidth among three for lower values of power supplies and bias current, thus more efficient.

Table 1. Parameter Values for Different Technologies

\begin{tabular}{|l|r|r|r|}
\hline Technology & $180 \mathrm{~nm}$ & $90 \mathrm{~nm}$ & $45 \mathrm{~nm}$ \\
\hline Vdd & $1.25 \mathrm{~V}$ & $0.9 \mathrm{~V}$ & $0.45 \mathrm{~V}$ \\
\hline Vss & $1.25 \mathrm{~V}$ & $0.9 \mathrm{~V}$ & $0.45 \mathrm{~V}$ \\
\hline Bias Current $\left(I_{B 1}\right)$ & $50 \mu \mathrm{A}$ & $50 \mu \mathrm{A}$ & $40 \mu \mathrm{A}$ \\
\hline Bias Current $\left(I_{B 2}\right)$ & $80 \mu \mathrm{A}$ & $60 \mu \mathrm{A}$ & $40 \mu \mathrm{A}$ \\
\hline Band Width $(\mathrm{GHz})$ & 6.6 & 15 & 33 \\
\hline
\end{tabular}


The universal biquad filter circuit of Fig. 3 is simulated using HSPICE in $45 \mathrm{~nm}$ technology. The high-pass, low-pass, band-pass and band-stop responses are shown in Fig. 5(a). Effect of variation in the filter characteristics with bias current $I_{B 1}$ and $I_{B 2}$ of the MOCCCDTA was also explored using HSPICE simulations. Fig. 5(b) depicts the change in various filter characteristics as the bias currents is varied from 10A to 50A in steps of 10A for all the four filter functions.
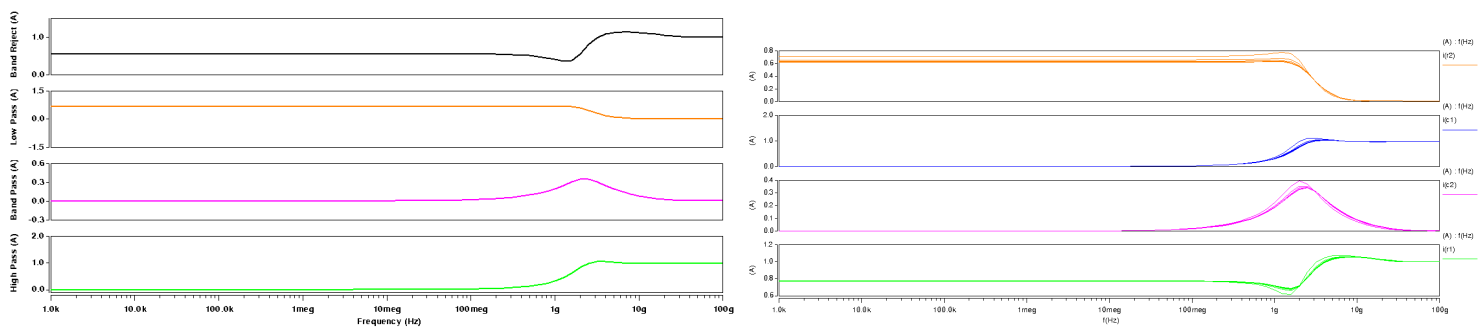

(a) Band-Reject, Low-Pass, Band-Pass and High-Pass Filter Re- (b) Variation in Filter Responses with the Variation in Bias Cursponses rents

Figure 5. Results of Responses of Filter in Fig. 3: (a)Filter Responses in $45 \mathrm{~nm}$ Technology and (b)Responses of various filter functions with the variation of bias currents from $10 \mu \mathrm{A}$ to $50 \mu \mathrm{A}$ in steps of $10 \mu \mathrm{A}$

Table 2 shows the values of peak-frequency and bandwidth obtained from the universal biquad filter of Fig. 3. It is observed that the frequency obtained is in GHz. Thus the filter is suitable for high frequency applications.

Table 2. Peak-frequency and 3dB bandwidth of Universal Biquad Filter

\begin{tabular}{|l|r|r|r|}
\hline Filter & Low-Pass & High-Pass & Band-Pass \\
\hline Peak Frequency $(\mathrm{GHz})$ & 1.27 & 3.34 & 2.36 \\
\hline Bandwidth $(\mathrm{GHz})$ & 2.44 & 1.95 & 2.71 \\
\hline
\end{tabular}

The present work [7, 12-15] has also been compared with the work done in the previous year on different technologies according to the active element used, bias currents, passive elements used etc. THe comparison has been shown in table 6.

\begin{tabular}{|c|c|c|c|c|c|}
\hline & Technology & $\begin{array}{c}\text { Active } \\
\text { Building Block } \\
\end{array}$ & $\begin{array}{c}\text { Passive } \\
\text { Components }\end{array}$ & Bias Currents & Bandwidth \\
\hline [13] & $360 \mathrm{~nm}$ & CCCDTA & $\begin{array}{l}\mathrm{C} 1=\mathrm{C} 2=0.16 \mathrm{nF} \\
\mathrm{Rp}=\mathrm{Rn}=821-25.1 \mathrm{~K} \Omega\end{array}$ & $\mathrm{lb} 1=\mathrm{lb} 2=50 \mu \mathrm{A}$ & $282 \mathrm{MHz}$ \\
\hline [17] & $350 \mathrm{~nm}$ & CDTA & $\begin{array}{l}\mathrm{C} 1=\mathrm{C} 2=1 \mathrm{nF} \\
\mathrm{R} 1=\mathrm{R} 2=1 \mathrm{k} \Omega\end{array}$ & $\begin{array}{l}\mathrm{Ib} 1=\mathrm{Ib} 2=100 \mu \\
\mathrm{A}\end{array}$ & $130 \mathrm{kHz}$ \\
\hline [18] & $350 \mathrm{~nm}$ & FDCCII & $\begin{array}{l}\mathrm{C} 1=\mathrm{C} 2=0.16 \mathrm{nF} \\
\mathrm{R} 1=\mathrm{R} 2=0.71 \mathrm{k} \Omega\end{array}$ & $\mathrm{lb} 1=\mathrm{lb} 2=35 \mu \mathrm{A}$ & $1 \mathrm{MHz}$ \\
\hline [19] & $350 \mathrm{~nm}$ & CCCCTA & $\mathrm{C} 1=\mathrm{C} 2=7.5 \mathrm{pF}$ & $\mathrm{lb} 1=\mathrm{lb} 2=7.5 \mu \mathrm{A}$ & $1.8 \mathrm{MHz}$ \\
\hline [20] & $250 \mathrm{~nm}$ & CCDDCCTA & $\begin{array}{l}\mathrm{C} 1=\mathrm{C} 2=100 \mathrm{pF} \\
\mathrm{R} 1=\mathrm{R} 2=1 \mathrm{k} \Omega\end{array}$ & $\begin{array}{l}\mathrm{lb} 1=25 \mu \mathrm{A} \\
\mathrm{lb} 2=200 \mu \mathrm{A}\end{array}$ & $1.28 \mathrm{MHz}$ \\
\hline [21] & $180 \mathrm{~nm}$ & VDTA & $\begin{array}{l}\mathrm{C} 1=\mathrm{C} 2=0.01 \mathrm{nF} \\
\mathrm{R}=1.58 \mathrm{k} \Omega\end{array}$ & $\begin{array}{l}\mathrm{Ib} 1=150 \mu \mathrm{A} \\
\mathrm{lb} 2=42.38 \mu \mathrm{A}\end{array}$ & $1 \mathrm{MHz}$ \\
\hline $\begin{array}{l}\text { This } \\
\text { Work }\end{array}$ & $45 \mathrm{~nm}$ & MOCCCDTA & $\mathrm{C} 1=10 \mathrm{fF} \mathrm{C} 2=3 \mathrm{fF}$ & $\begin{array}{l}\mathrm{lb} 1=20 \mu \mathrm{A} \\
\mathrm{lb} 2=10 \mu \mathrm{A}\end{array}$ & $2.71 \mathrm{GHz}$ \\
\hline
\end{tabular}

Figure 6. Comparison of the present work with the previous works 


\subsection{TUNING OF BAND PASS FILTER FOR BLUETOOTH APPLICATION}

Bluetooth is a wireless technology standard for exchanging data over short distances using short-wavelength UHF radio waves in the ISM band from 2.4 to $2.485 \mathrm{GHz}$ from fixed and mobile devices, and building personal area networks (PANs). Invented by telecom vendor Ericsson in 1994, it was originally conceived as a wireless alternative to RS-232 data cables. It can connect several devices, overcoming problems of synchronization. The universal filter circuit of Fig. 3 is also tuned for Bluetooth applications. The simulation result for the tuning of the filter for Bluetooth application is shown in Fig. 7.

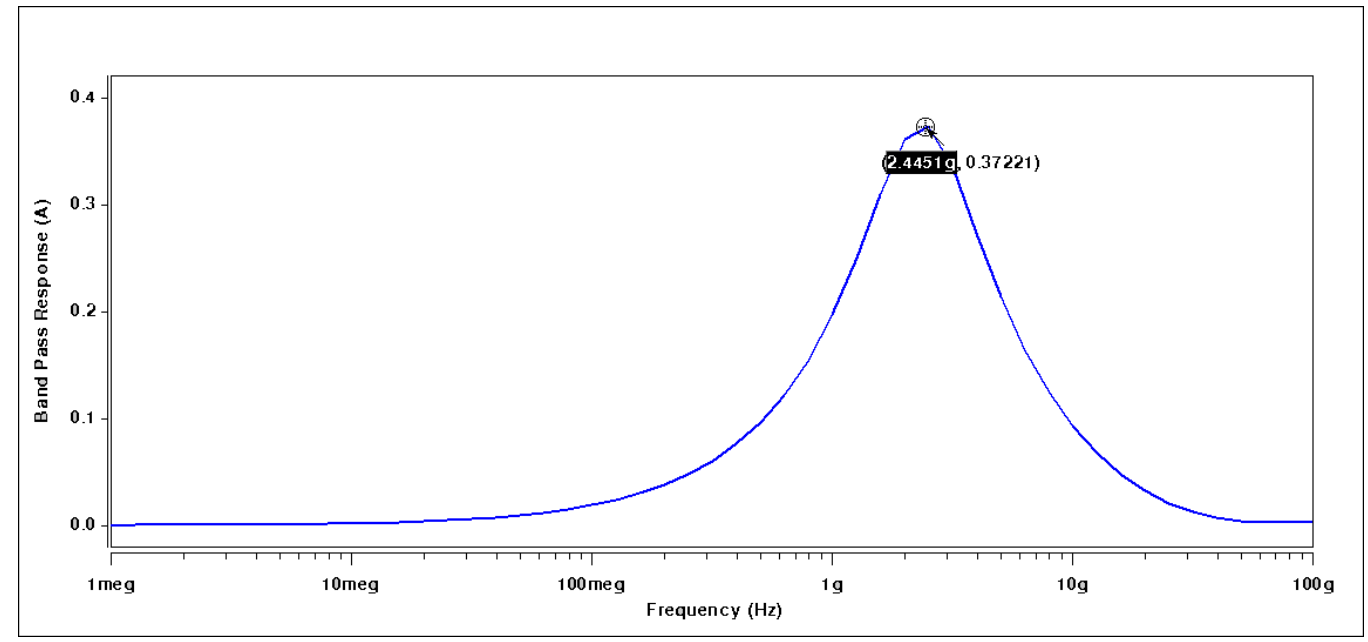

Figure 7. Tuning of Band Pass Filter for Bluetooth Applications

\section{CONCLUSION}

A CMOS-based implementation of multi output current controlled current differencing transconductance amplifier (MOCCCDTA) was presented. The performance comparison of MOCCCDTA has been done by performing transient and AC analyses for 180nm, 90nm and 45nm CMOS technology nodes using HSPICE simulations. It was found that the MOCCCDTA circuit offers highest bandwidth at 45nm CMOS technology node. A current mode universal biquad filter was then discussed that employs a MOCCCDTA as an active element and two grounded capacitors. The filter provides low-pass, high-pass, band-pass and band-reject responses. Also the tunability of the low-pass, highpass, band-pass and band-reject filter was analysed by varying the bias current. Next the tunability of the filter for the Bluetooth application has been discussed. The filter circuit is suitable for high frequency Bluetooth applications. 


\section{REFERENCES}

[1] P.E. Allen and D.R. Holberg. CMOS analog circuit design. New York: Oxford University Press, 2002.

[2] David A. Johns and Ken Martin. Analog integrated circuit design. Wiley India Pvt. Ltd., 1997.

[3] K. Bult. Analog design in deep sub-micron cmos. Proc. European Solid-State Conf, pages 126-132, 2001.

[4] J. R. Angulo, R.G. Carvajal, and A. L. Martin. Techniques for the design of low voltage power efficient analog and mixed signal circuits. 22nd International Conference on VLSI Design, 26, No. 27:5-9, Jan. 2009.

[5] Lattenberg and Vrba. Filters with current amplifiers for high-speed communication. International Conference on Systems and Mobile Communications and Learning Technologies, 150, No. 150:23-29, Apr. 2006.

[6] H. H. Kuntman and A. Uygur. New possibilities and trends in circuit design for analog signal processing. International Conference on Applied Electronics, 1, No. 9:5-7, Sept. 2012.

[7] Sajai Vir Singh, Sudhanshu Maheshwari, and Durg Singh Chauhan. Single MO-CCCCTA based electronically tunable current tranimpedence mode biquad universal filter. Journal of Circuits and Systems, 2:1-6, 2011.

[8] A. Bhatt. Design and analysis of cmos current conveyor. Journal of Information, Knowledge and Research in ECE, 2, Issue 2, Oct. 2013.

[9] J. Sharma, M. S. Ansari, and J. B. Sharma. Electronically tunable resistor-less universal filter in $0.5 \mathrm{v} 32 \mathrm{~nm}$ CNFET. Fifth International Symposium on Electronic System Design (ISED), page 206207, Dec. 2014.

[10] J. Sharma, M. S. Ansari, and J. B. Sharma. Current-mode electronically tunable resistor-less universal filter in $0.5 \mathrm{v} 32 \mathrm{~nm}$ CNFET. International Conference on Devices, Circuits and Communications (ICDCCom), page 16, Sept. 2014.

[11] Montree Siripruchyanun and Wanai Jaikla. Cmos current controlled current differencing transconductance amplifier and applications to analog signal processing. International Journal of Electronics and Communications (AEU), 62:277-287, 2007.

[12] Anisur Rehman Nasir and S.N.Ahmad. Single CDTA based current- mode universal filter with grounded capacitors. International Journal Of Electronics Engineering, 4:73-75, 2012.

[13] Ajay Kumar Kushwala and Sajal K.Paul. Current mode universal filter using single CCDDCCTA. Journal of Circuits and Systems, 6:224-236, 2015.

[14] Dinesh Prasad, Data Ram Bhaskar, and Mayank Srivastava. Universal current mode biquad filter using a VDTA. Journal of Circuits and Systems., 4:29-33, 2013.

[15] Raj Senani, Kasim Karam Abdalla, and Data Ram Bhaskar. A state variable method for realisation of universal current mode biquads. Journal of Circuits and Systems, 2:286-292, 2011.

\section{BIOGRAPHIES OF AUTHORS}

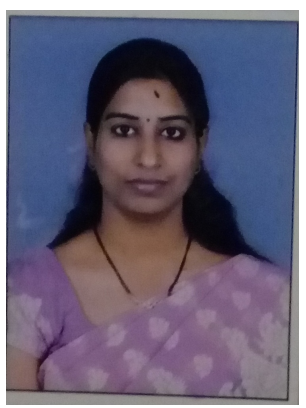

Jyoti Sharma is Assistant Professor in the Department of ECE at BIT MESRA, Jaipur Campus with Master of Technology from NIT, Jaipur. She is pursuing Ph.D. in the field of VLSI Circuit Design from BIT Mesra. Her researches are in fields of electronics, analog systems, VLSI Circuits, Nanotechnology, Current Mode Circuits. She is a member of the IETE(Institution for Electronics and Telecom engineers)

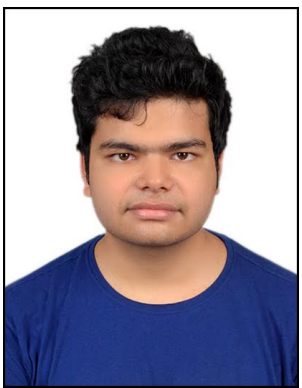

Shantanu Chakraborty is currently persuing his undergraduate degree of Bachelor Of Engineering in Electronics and Communication Engineering at BIT MESRA,Jaipur Campus. He is presently a student member of the IETE(Institution for Electronics and Telecom engineers) and has actively participated in National Students' Congress Forum organised by IETE at BIT MESRA. He is also actively involved in the technical committee of the University as a student coordinator.He has involved himself in minor project works in the institution as a student coordinator. 